\title{
O uso das Ferramentas na Educação a Distãncia e o Papel do Tutor
}

Francisca Auderlânia de Oliveira Dias; Adriana Maria Simião da Silva

\begin{abstract}
Resumo: Este artigo busca apresentar a importância do papel do professor-tutor na modalidade à distância e as ferramentas que a acompanha, considerando sua experiência vivida no decorrer de sua vida acadêmica. Através do surgimento das novas tecnologias a internet tornou-se um meio propício para a difusão do conhecimento, aumentando a oferta de cursos superiores à distância, nesse contexto o tutor é responsável por manter uma comunicação ativa com seus alunos através das ferramentas, por isso propomos neste artigo reflexões que abordem a importância do professor-tutor nessa modalidade, destacando suas principais características e funções e as ferramentas utilizadas no ensino à distância. A metodologia utilizada foi a pesquisa bibliográfica, e teve como objetivo descrever e analisar o sistema de tutoria na Educação a Distância bem como suas ferramentas , destacando o importante trabalho do professor-tutor, averiguando suas características e suas qualidades .Concluiu- se também que com esse estudo, contribuiu para repensar a função dos tutores presenciais e a distância atuantes na modalidade de ensino à distância ,utilizando-se das ferramentas tecnológicas , tendo em vista que, acreditamos ser de fundamental importância a realização de formação inicial e continuada com esses profissionais, pois são eles que mantêm contato direto e diário com os alunos.
\end{abstract}

Palavras-Chave:Ferramentas. Educação a Distancia. Professor. Tutor

\section{The use of Tools in Distance Education and the Tutor's Role}

\begin{abstract}
This article aims to present the importance of the teacher-tutor role in distance mode and tools that goes with it, considering his experience lived throughout his academic life. Through the emergence of new technologies the internet has become a means conducive to spreading knowledge, increasing the supply of courses greater than the distance in this context the tutor is responsible for maintaining active communication with students through the tools, so we propose this article thoughts that address the importance of teacher-tutor in this modality, highlighting its key features and functions and the tools used in distance learning. The methodology used was literature, and aimed to describe and analyze the mentoring system in Distance Education and its tools, highlighting the important work of the teacher-tutor, checking its characteristics and its .Concluiuqualities too that with this study contributed to rethink the function of the present tutors and distance working in the mode of education at a distance, using the technological tools with a view that we believe are fundamental to conducting initial and ongoing training to these professionals, it is they who have direct and daily contact with students.
\end{abstract}

Keywords: Tools. Distance Education. Professor . Tutor

\section{Introdução}

O presente artigo tem por objetivo descrever e analisar o sistema de tutoria na Educação a Distância bem como suas ferramentas, destacando o importante trabalho do professor-tutor, averiguando suas características e suas qualidades.

\footnotetext{
Graduada em Pedagogia pela Universidade Vale do Acarau. E-mail:audelania_dias@hotmail.com

Professora orientadora do Trabalho de Conclusão de Curso. Graduação em Ciências Sociais. Universidade Federal do Ceará, UFC, Brasil. Mestrado em Sociologia . Universidade Federal do Ceará, UFC, Brasil. E_mail :adrianamsimiao@gmail.com
} 
Trata-se de uma pesquisa bibliográfica sobre as possibilidades do trabalho de tutoria na educação a distância. O tema é considerado no contexto da modalidade de ensino, e privilegia o papel e a importância do tutor.

O trabalho deste profissional é analisado como responsável pela mediação nos ambientes virtuais de aprendizagem e que possibilitam a construção do conhecimento, de acordo com as ideias defendidas por Paulo Freire, ao estabelecer o conceito de comunicação dialógica. Para tanto, buscouse analisar as principais referências sobre educação a distância como artigos científicos, livros e manuais da área específica, com base nos principais autores e pesquisadores da área. Portanto, para que tudo isto seja concretizado, é preciso à criação de políticas para a prática na modalidade de EAD, visando alcançar os benefícios das ferramentas interativas no processo de ensino aprendizagem. Ter ambientes ricos em ferramentas interativas é importantes, mas, o mais importante é os profissionais estarem preparados para utilizar estes recursos a fim de promover as interações, cooperações de todos os envolvidos no processo de ensino e aprendizagem virtual

O objetivo dessa pesquisa é verificar a proposta de tutoria nos cursos superiores a distância, apresentando ações que descrevam e abordem essa modalidade e as relações de trabalho docente dos professores como parte de uma pesquisa que se encontra em desenvolvimento, pois é através da pesquisa que ampliamos nosso conhecimento a respeito do assunto abordado diante das questões sociais que marcam nosso país.

Antes de iniciarmos a descrição do artigo é importante refletirmos acerca do Ensino a distância na formação do aluno, partindo da importância do processo de formação do discente e seu ensino/aprendizagem.

A metodologia que foi utilizada neste artigo foi a pesquisa bibliográfica e teve como embasamento teórico os seguintes autores:Aretio (2007) A sua principal preocupação é com a solidão por parte dos educando, Freire (1980) O diálogo, em Freire, exige um pensar verdadeiro, um pensar crítico, Moraes e Vieira (2007)refere-se ao tutor e suas atribuições, Rodrigues (2004)fala sobre a educação a distancia no Brasil.

\section{Educação a Distância no Brasil}

O desenvolvimento da educação a distância aconteceu por meio de gerações, conforme as necessidades de ensino e as inovações tecnológicas e de comunicação de cada época. As gerações da educação a distância encontradas na literatura costumam diferir um pouco em suas definições e datas, porém geralmente são divididas em cinco. Conforme Rodrigues (2004, p.54) 
Id on Line Revista Multidisciplinar e de Psicologia

Id on Line Multidisciplinary Journal and Psycology

Quadro 01: Gerações em Educação a Distância.

\begin{tabular}{|c|c|l|}
\hline Geração & Período & \multicolumn{1}{c|}{ CARACTERISTICAS } \\
\hline $1 .^{\text {a }}$ & Até 1970 & $\begin{array}{l}\text { Estudo por correspondência. A comunicação se dava pelo uso } \\
\text { exclusivo de material impresso, geralmente um guia de estudo } \\
\text { com exercícios, enviado pelo correio. }\end{array}$ \\
\hline $2^{\text {a }}$ & 1970 & $\begin{array}{l}\text { Surgimento das primeiras Universidades Abertas, com design e } \\
\text { implementação sistematizados de cursos a distância, utilizando, } \\
\text { além do material impresso, transmissões por televisão aberta e } \\
\text { rádio; uso de fitas de áudio e vídeo, com interação aluno-tutor } \\
\text { por telefone ou nos centros de atendimento. }\end{array}$ \\
\hline $3^{\text {a }}$ & 1990 & $\begin{array}{l}\text { Uso de computadores, com estações de trabalho multimídia e } \\
\text { redes de conferência. }\end{array}$ \\
\hline $4^{\text {a }}$ & 2000 & $\begin{array}{l}\text { Aumento da capacidade de processamento dos computadores e } \\
\text { da velocidade das linhas de transmissão, o que interfere na } \\
\text { apresentação do conteúdo e interações. Acesso a bancos de } \\
\text { dados e bibliotecas eletrônicas. }\end{array}$ \\
\hline $5^{\text {a }}$ & Atualmente & $\begin{array}{l}\text { Uso de agentes inteligentes, equipamentos wireless e linhas de } \\
\text { transmissão eficientes. Organização e reutilização dos } \\
\text { conteúdos. }\end{array}$ \\
\hline
\end{tabular}

Fonte: Rodrigues (2004, p.54).

O Quadro 01 revela que a educação a distância evoluiu muito ao longo dos anos, e que esta modalidade de ensino não é uma prática nova Surgiu no Brasil por volta de 1900, com o avanço dos serviços de correio, e foi evoluindo com o desenvolvimento de novas tecnologias, possibilitando assim uma inclusão cada vez maior de estudantes na educação a distância.

Para Moraes e Vieira (2009):

No Brasil, a experiência pioneira de $\mathrm{EaD}$ foi com o uso do rádio, com a criação da Fundação da Rádio Sociedade do Rio de Janeiro, em 1923, que transmitia programas de literatura, radiotelegrafia e telefonia, línguas, entre outros. O Instituto Universal Brasileiro (IUB), fundado em 1941, marcou o início dos cursos baseados na mídia impressa. Ainda hoje atuando, o IUB é uma empresa privada que oferece Ensino a Distancia de caráter supletivo, além de vários cursos profissionalizantes. Em 1939, foi criado o Instituto Radio Monitor e, logo em seguida, houve as experiências radiofônicas do MEB e do Projeto Minerva (MORAES e VIEIRA, 2009, p.15)

Conforme Lobo Neto (2003), do ponto de vista legal, a educação a distância foi regulamentada no Brasil apenas em 1996, por meio da Lei de Diretrizes e Bases da Educação Nacional (Lei nº 9.394, de 20 de dezembro de 1996), e foi normatizada pelos Decretos $n^{\circ} .2 .494$ (de 10 de fevereiro de 1998) e $n^{\circ} .2 .561$ (de 27 de abril de 1998) e pela Portaria Ministerial $n^{\circ} .301$ (de 7 de abril de 1998). Sobre a educação a distância, a Lei no 9.394/96 faz referencia especialmente em seu art. 80, destacando que: 
Art. 80. O Poder Público incentivará o desenvolvimento e a veiculação de programas de ensino a distância, em todos os níveis e modalidades de ensino, e de educação continuada.

$\S 1^{\circ}$ A educação a distância, organizada com abertura e regime especiais, será oferecida por instituições especificamente credenciadas pela União.

$\S 2^{\circ}$ A União regulamentará os requisitos para a realização de exames e registro de diploma relativos a cursos de educação a distância.

$\S 3^{\circ}$ As normas para produção, controle e avaliação de programas de educação a distância e a autorização para sua implementação, caberão aos respectivos sistemas de ensino, podendo haver cooperação e integração entre os diferentes sistemas.

$\S 4^{\circ}$ A educação a distância gozará de tratamento diferenciado, que incluirá:

I - custos de transmissão reduzidos em canais comerciais de radiodifusão sonora e de sons e imagens;

II - concessão de canais com finalidades exclusivamente educativas;

III - reserva de tempo mínimo, sem ônus para o Poder Público, pelos concessionários de canais comerciais. (BRASIL, 1996).

O Ministério da Educação, em 1997, instituiu um grupo de especialistas para regulamentar o art. 80 da LDB, surgindo assim os Decretos 2.494 e 2.561, em fevereiro e abril de 1998, respectivamente, e a portaria 301, de 7 de abril de 1998, normatizando assim os procedimentos que deveriam ser adotados pelas instituições para obter o credenciamento do MEC para a oferta de cursos de graduação a distância. O Conselho Nacional de Educação, em abril de 2001, editou a Resolução 01, que disciplina a oferta dos cursos de pós-graduação a distância no país, fixa limites e estabelece exigências para o reconhecimento de cursos a distância ofertados por instituições estrangeiras. No mesmo ano o Ministério da Educação publicou a portaria 2.253, que admite oferecer até $20 \%$ da carga horária de cursos já reconhecidos, na modalidade a distância, às universidades, centros universitários, faculdades e centros tecnológicos.

A regulamentação da educação a distância no Brasil proporcionou aos adultos que trabalham, às pessoas que não podem sair de casa, às pessoas que se encontram distantes de instituições de ensino, etc., tornarem-se incluídas academicamente e digitalmente.

\section{A Tutoria}

A tutoria é uma atividade de interação pedagógica, necessária para orientar, conduzir e supervisionar o processo de ensino-aprendizagem. Para Geibet al (2007), a tutoria significa "cuidar, proteger, amparar, defender e assistir, tendo a atividade tutorial, no âmbito da educação, o sentido de acompanhamento próximo, orientação sistemática de grupos de alunos, realizada por pessoas experientes na área de formação".

Considerando-se os objetivos de um curso a distância, em que o aluno deve construir seu conhecimento acerca dos assuntos abordados, surge neste importante processo a pessoa do tutor, que 
Id on Line Revista Multidisciplinar e de Psicologia

Id on Line Multidisciplinary Journal and Psycology

deve guiar e realizar a função de orientador e gerador de discussões (GEIB et al. (2007). Deve ainda ser capaz de indicar fontes bibliográficas e assumir outras tarefas na função de tutoria, como: "proteção, defesa, amparo, direção ou, mesmo, tutela de alguém, devendo desenvolver capacidades, valores, atitudes, disposição e estratégias motivacionais de apoio à autonomia de seus alunos".

No Sistema UAB, o tutor é um profissional selecionado pelas instituições públicas de ensino superior (IPES), para realizar as atividades características de tutoria, sendo necessário formação de nível superior e experiência mínima de 1 (um) ano no magistério do ensino básico ou superior, ou ter formação pós-graduada, ou estar vinculado a programa de pós-graduação (BRASIL, 2009).

Segundo Moraes e Vieira (2007), o tutor é um intermediário entre os professores, alunos e a instituição de ensino. O tutor auxilia no processo de ensino e aprendizagem, esclarecendo dúvidas de conteúdo e dúvidas administrativas, colabora no reforço da aprendizagem, além de ser responsável por estar sempre motivando os alunos, evitando assim a evasão no decorrer do curso.

Os Referenciais de Qualidade para Educação Superior a Distância (BRASIL, 2007) descrevem o tutor como essencial nos processos de aprendizagem, acompanhamento e avaliação, compreendendo o tutor como:

[...] um dos sujeitos que participa ativamente da prática pedagógica. Suas atividades desenvolvidas a distância e/ou presencialmente devem contribuir para o desenvolvimento dos processos de ensino e de aprendizagem e para o acompanhamento e avaliação do projeto pedagógico (BRASIL, 2007 p. 21).

Desta forma, percebe-se que os tutores podem ser presenciais ou a distância. Os tutores presenciais são responsáveis pelo atendimento aos alunos no polo de apoio, e atendem em média 25 alunos por polo. Aplicar as avaliações presenciais das disciplinas, acompanhar e coordenar as videoconferências e organizar grupos de estudo com os alunos estão entre as principais atribuições específicas do tutor presencial.

Este trabalho tem enfoque no tutor a distância que, conforme Moraes e Vieira (2007), é "o elo com o professor do curso e garante que professores e alunos tenham todas as informações necessárias para atuar com desenvoltura no processo de ensino-aprendizagem".

Algumas atribuições são comuns entre o tutor presencial e o tutor a distância, como: manter contato constante com o aluno, orientar o aluno no planejamento das atividades, esclarecer dúvidas sobre regulamento e procedimentos do curso, etc. As tarefas a serem executadas pelos tutores estão detalhadas no Manual de Atribuições dos Bolsistas UAB, que não faz distinção entre tutor presencial e a distância. As atribuições são:

- mediar a comunicação de conteúdos entre o professore os cursistas;

- acompanhar as atividades discentes, conforme o cronograma do curso;

- apoiar o professor da disciplina no desenvolvimento das atividades docentes; 
Id on Line Revista Multidisciplinar e de Psicologia

Id on Line Multidisciplinary Journal and Psycology

- manter regularidade de acesso ao AVA e dar retorno às solicitações do cursista no prazo máximo de 24 horas;

- estabelecer contato permanente com os alunos e mediar as atividades discentes;

- colaborar com a coordenação do curso na avaliação dos estudantes;

- participar das atividades de capacitação e atualização promovidas pela Instituição de Ensino;

- elaborar relatórios mensais de acompanhamento dos alunos e encaminhar à coordenação de tutoria;

- participar do processo de avaliação da disciplina sob orientação do professor responsável;

- apoiar operacionalmente a coordenação do curso nas atividades presenciais nos pólos, em especial na aplicação de avaliações.

Apesar do Manual de Atribuições dos Bolsistas não fazer distinção entre as atribuições de cada tutor, os Referenciais de Qualidade para Educação Superior a Distância (BRASIL, 2007) consideram como pertinente ao tutor a distância: esclarecer dúvidas por meio de fóruns de discussão existentes na plataforma virtual; participar de videoconferências; promover espaços de construção coletiva de conhecimento; selecionar material de apoio e sustentação teórica aos conteúdos, além de participar dos processos avaliativos de ensino-aprendizagem, juntamente com os docentes.

Tendo em vista que estudar a distância implica em diversas mudanças não somente para o estudante, mas também para o professor, para a organização de ensino e, principalmente, para a empresa, é necessário trabalharmos buscando condições para que a oferta de cursos a distância não seja prejudicada mediante deficiências de atendimento e dificuldades de sanar dúvidas que naturalmente surgem à medida que os cursos são realizados. A tutoria, neste caso, costuma ser considerada peça-chave na ação de aprendizagem. Tal assertiva é válida, pois o tutor, pessoa responsável por fazer todo o acompanhamento do estudante ao longo do curso, é quem deve criar condições mínimas para que uma pessoa que estude a distância não sinta tanta diferença em relação ao estudo presencial.

De acordo com Aretio (2002, p. 117): “[...] um dos problemas que os estudantes da modalidade a distância mais acusam é a solidão e o distanciamento do professor e dos companheiros de estudo".

Logo, vamos partir da premissa de que o tutor fará com que o aluno não se sinta só. Dependendo da tecnologia e do desenho instrucional do curso, os estudantes poderão se sentir fisicamente distantes, porém com alto grau de interação e com amplas curso e, principalmente, com os 
tutores. A palavra tutor, segundo, faz referência à pessoa que exerce a proteção, a tutela, defesa ou salvaguarda de uma pessoa menor ou necessitada, em sua primeira concepção. O tutor é aquela pessoa que auxilia o estudante em todos os momentos do curso que envolvem a aprendizagem. É a pessoachave no curso, que tem a preocupação de tornar o seu estudo mais agradável e completo, ou seja, é a pessoa que lhe incentiva.

Para tanto, todo tutor deve apresentar algumas características que o possibilitem realizar esse atendimento. São características voltadas para o pleno exercício das tarefas e estão balizadas na tríade conhecimento, habilidades e atitudes. Veja no Quadro 2:

Quadro2: Características fundamentais para o tutor

\begin{tabular}{|c|c|}
\hline \multicolumn{2}{|r|}{ CARACTERISTICAS FUNDAMENTAIS PARA O TUTOR } \\
\hline $\begin{array}{c}\text { Autenticidade } \\
\text { e honradez }\end{array}$ & $\begin{array}{l}\text { Um tutor necessita apresentar estas características, pois deve ser autêntico o } \\
\text { suficiente para não se deixar influenciar por pressões externas, bem como para } \\
\text { que consiga fazer o melhor julgamento possível. A honradez, nesse sentido, se } \\
\text { refere às questões relacionadas ao compromisso que ele assumirá, pois a ação de } \\
\text { tutoria está balizada em um acompanhamento contínuo. }\end{array}$ \\
\hline $\begin{array}{l}\text { Maturidade } \\
\text { Emocional }\end{array}$ & $\begin{array}{l}\text { A maturidade emocional está relacionada também com questões voltadas a } \\
\text { atitudes. É necessário entender o outro lado. Geralmente, o estudante a distância, } \\
\text { no início do curso, por não estar habituado com uma nova rotina, costuma } \\
\text { transmitir sinais de desmotivação ou de fraqueza emocional. A partir do } \\
\text { momento em que um tutor tem maturidade suficiente para trabalhar esses } \\
\text { aspectos com os estudantes, cria-se uma chance maior de se construir um } \\
\text { relacionamento mais profícuo e duradouro. }\end{array}$ \\
\hline $\begin{array}{c}\text { Inteligência } \\
\text { e rapidez } \\
\text { mental }\end{array}$ & $\begin{array}{l}\text { Dos pontos apresentados até o momento, este, de fato, é um dos mais } \\
\text { importantes. A rapidez mental é pertinente, pois o tutor deverá responder às } \\
\text { mensagens o quanto antes, mas com um nível de aprofundamento considerável. } \\
\text { Para tanto, deve saber ligar todo o seu conhecimento no intuito de, no primeiro } \\
\text { momento, ler, interpretar e depois conflitar a resposta com o padrão } \\
\text { preestabelecido e uma vez que deve-se satisfazer às necessidades de aprendizado } \\
\text { do estudante. }\end{array}$ \\
\hline $\begin{array}{l}\text { Capacidade } \\
\text { de escuta }\end{array}$ & $\begin{array}{l}\text { O tutor é, em muitos casos, aquela pessoa que pode ser comparada com um } \\
\text { psicólogo ou um grande amigo. Por quê? Porque ele deve lhe escutar! Ele deve } \\
\text { saber escutar as suas angústias, seus receios, suas dificuldades e inclusive, em } \\
\text { função desta postura, deve estimulá-lo ao máximo a continuar manifestando os } \\
\text { seus sentimentos. É através de uma boa capacidade de escuta que o tutor acaba } \\
\text { construindo, consolidando, o seu relacionamento com os alunos. }\end{array}$ \\
\hline $\begin{array}{c}\text { Capacidade } \\
\text { de comunicação }\end{array}$ & $\begin{array}{l}\text { Assim como saber escutar, o tutor deve saber se comunicar. Esse, geralmente, é } \\
\text { um grande desafio. As mensagens, dependendo da forma como são transmitidas, } \\
\text { podem ser interpretadas de maneiras distintas. Isso tende a ser perigoso para } \\
\text { ambas as partes envolvidas no processo de ensino-aprendizagem, pois, pelo fato } \\
\text { de estarem a distância, sem o contato visual ou então sem a possibilidade de } \\
\text { interagir de maneira síncrona, por exemplo, todo o contexto pode ficar } \\
\text { comprometido. Por outro lado, durante a codificação da mensagem, o emissor } \\
\text { pode escolher mal as suas palavras e não conseguir se fazer entender. A } \\
\text { recíproca também é verdadeira. Logo, a capacidade de comunicação é de suma } \\
\text { importância para que a relação continue positiva entre as partes envolvidas. }\end{array}$ \\
\hline
\end{tabular}


Id on Line Revista Multidisciplinar e de Psicologia

Id on Line Multidisciplinary Journal and Psycology

\begin{tabular}{|c|l|}
\hline \multirow{3}{*}{$\begin{array}{c}\text { Organização } \\
\text { e controle }\end{array}$} & $\begin{array}{l}\text { A capacidade de se organizar e a de controlar bem as atividades desenvolvidas } \\
\text { pelo estudante também interferem nos resultados da tutoria. Isso acontece uma } \\
\text { vez que, durante a realização dos cursos, o aluno tende a encaminhar diversos } \\
\text { trabalhos ou então a manifestar algumas dúvidas. Um tutor desorganizado e que } \\
\text { não consiga realizar as atividades de controle certamente lhe cobrará algo que já } \\
\text { pode ter sido feito e encaminhado a ele. Com isso, a sua relação de confiança } \\
\text { tende a diminuir e, de certa maneira, comprometer o sucesso do curso. }\end{array}$ \\
\hline \multirow{5}{*}{ Segurança que a relação de tutoria envolve a solução de dúvidas ou então o } \\
acompanhamento contínuo dos estudantes, na da melhor do que trabalhar com \\
uma pessoa que, mesmo a distância, se mostre segura o suficiente para lhe \\
auxiliar. Torna-se complicado manifestar os nossos anseios quando no outro lado \\
existe uma pessoa que não conhece plenamente o assunto ou não demonstra \\
segurança suficiente para nos auxiliar. Portanto, faça o teste com o seu tutor. \\
Veja se ele lhe transmite a segurança necessária para continuar os seus estudos. \\
Analise suas respostas, veja se ele lhe estimula a ir além, se ele apresenta \\
domínio da situação. Procure conseguir o máximo de rendimento dele!
\end{tabular}

Fonte: Adaptado de Aretio (2002), Rumble (2003), Gonzalez (2005) e Knaesel, Meed e Rossetti (2000)

Dentro desta visão que é a abordagem dialógica,a base do diálogo e da interação a relação com o outro, isto requer do tutor que ele tenha em seu perfil habilidades necessárias como: facilidade de comunicação, dinamismo, liderança e iniciativa, saber ouvir, sendo empático e mantendo postura de cooperação, de participação, de tomada de consciência e elaboração dos próprios projetos de vida; competência individual e de equipe, para analisar realidades, formulando planos de ação coerentes, mantendo atitude reflexiva e com criticidade de forma ponderada, sobre a teoria e a prática educativa envolvida no processo; Sendo o mediador entre o saber e o aprendiz, deve o tutor ter consciência de que não é o detentor exclusivo do conhecimento, mas, sim, uma ponte para a fluência dos saberes em construção.

\section{O Tutor e a Comunicação Dialógica: Cliques para a Construção do Conhecimento}

A todos esses requisitos, que marcam o papel e a importância do tutor nas práticas de EAD, soma-se o do responsável pela comunicação, pela interação. Essa ideia, a nosso ver, ganha relevo nos fundamentos da comunicação dialógica defendida por Freire (1983), dentre outras publicações relacionadas à Pedagogia que liberta, que transforma, que coloca o aprendiz como sujeito, aqui sintetizada no que defende o autor: "não é no silêncio que os homens se fazem, mas na palavra, no trabalho, na ação-reflexão" (FREIRE, 1987, p. 78).

Acreditamos que a dialogicidade seja possível nos ambientes de aprendizagem apoiados nas mídias em educação. Isso depende, fundamentalmente, de ação humana: do sujeito que aprende e do sujeito que acompanha, que mobiliza para isso. 
Nesse sentido, recorremos ao pensamento de Pernías (2002), que, ao ser indagado sobre qual a vantagem de uma educação onde os alunos e os professores estão envolvidos com a tecnologia, respondeu:

\begin{abstract}
A melhor e maior vantagem é que os alunos podem ser atendidos de maneira mais personalizada e o professor estabelece laços que quando estava diante deles não teria feito. A tecnologia nos permite isso. De alguma forma, professores e alunos, utilizando a tecnologia podem ir "além das montanhas". Isso já era possível na pedagogia clássica porque os alunos podiam trocar cartas com os que estão do outro lado da montanha. Hoje em dia, graças à tecnologia e à internet, não é só possível escrever nossas cartas como também conhecer as outras pessoas num tempo muito mais reduzido, o que permite uma aproximação maior com elas. (PERNÍAS, 2002, p. 23).
\end{abstract}

Desse modo, é possível ratificar que, como promotor de laços e vínculos, o tutor responsabilizar-se-á pela criação de um ambiente acolhedor, confortável e propício à aprendizagem. E é esse um dos pontos vitais para a construção de conceitos sobre a dialogicidade, a comunicação e a interação que devem constituir o trabalho docente do tutor.

Segundo Freire (1980, p. 82), o diálogo é o encontro entre os homens, mediatizados pelo mundo, para designá-lo. Nessa linha de raciocínio, o autor coloca que este diálogo não pode significar o depósito de ideias em outros, nem tão pouco resumir-se a simples intercâmbio de ideias a serem consumidas por permutantes.

Logo mais, Freire (p. 83) assegura que o diálogo não se restringe à discussão hostil, polêmica àquilo com o que os homens não estão comprometidos e, como tal, não pode acontecer sem estar impregnado de amor, fundamento do e o próprio diálogo.

O tutor, preparado para exercer a mediação no processo de ensino e aprendizagem, tem condições para fazer a leitura dessas falas e, a partir delas, organizar, planejar ações que permitam a sua interação com os sujeitos da aprendizagem, no sentido de lhes fornecer referenciais de apoio para que os mesmos possam construir o conhecimento.

Considerando que a EaD é uma relação educativa mediada e mediatizada entre o professor (autor/ tutor/ especialista) e estudantes, em momentos e espaços diferentes do ensino presencial, apoiado por meios diversos e diferenciados (PRETI, 1996); concebemos que, no cenário da EaD, os personagens de sala de aula, professor e aluno não se materializam no tempo e no espaço, conforme ocorre no ensino presencial. Eles não deixam de existir, mas assumem características e funções específicas para essa modalidade de ensino.

Por conta disso, uma das mais importantes características da EaD é a organização de um sistema de apoio ao estudante, que deve ser amparado pela instituição formadora/EaD, no sentido de que esta forneça os mais variados tipos de suporte, do cognitivo ao afetivo, do social ao 
Id on Line Revista Multidisciplinar e de Psicologia

Id on Line Multidisciplinary Journal and Psycology

administrativo, do motivacional ao avaliativo, do comunicacional ao pedagógico, entre outros e, recursos didáticos que permitam a interação entre os partícipes do processo de ensino e aprendizagem, de maneira que seja possível a construção do conhecimento, principal objetivo do processo educacional".

\section{O Trabalho do Tutor}

O ensino a distância requer adaptações tanto por parte do aluno quanto do professor. Ao passo que é importante para o estudante que ele desenvolva persistência e automotivação, o tutor precisa se tornar fluente com as novas tecnologias e elaborar eficientes estilos instrucionais a fim de amplificar o interesse e a motivação dos estudantes.

A partir das reflexões de Dantas e Troleis (2013), é possível inferir que um tutor é aquele que favorece processos formativos, coordena e medeia aprendizagem. Portanto, ser tutor é estar interessado em promover capacidades humanas do próximo - no caso, o aluno. É, de forma mais ampla, conhecer caminhos (previstos nas estratégias inicialmente traçadas) e estar atento a outras formas, ditas pelos alunos, de concepção de mundo.

Diante do exposto, é possível avaliar que o trabalho da tutoria exige uma tomada de decisão consciente daqueles que pretendem desenvolver a função de tutor virtual. Acerca dessa consciência se faz necessário refletir sobre a pessoa do tutor virtual. Mill et al (2008) apresentam algumas dicas para aqueles que, direta ou indiretamente, pretendem desenvolver atividades na $\mathrm{EaD}$, evidenciando a necessidade da "tutoria e de cuidados necessários aos tutores, como cultivar a ideia de um número de alunos adequado ao trabalho pedagógico; a negociação com os alunos sobre a disponibilidade de tempo/horário para acompanhamento e cuidar dos riscos à própria saúde é fundamental à qualidade de vida do tutor teletrabalhador (tutor virtual), entre outros cuidados" (MILL et al, 2008).

Acerca da função pedagógica, Pallof e Pratt (2002) propõem que o tutor é aquele que propicia aos cursistas um ambiente social estimulador da aprendizagem, utilizando recursos didáticos disponíveis pela mediação tutorial. Ele também atua mediante o agendamento de atividades do curso, acompanhamento sistemático dos cursistas, tempo de resposta e avaliação constante de sua prática e da participação dos alunos, além de possuir função técnica relacionada com o conhecimento técnico do tutor e seu potencial didático para compartilhá-lo com todos os cursistas.

Nogueira e Both (2012) classificam as competências pedagógicas, didáticas e linguísticas como fundamentais para explicação e orientação das atividades; a competência tecnológica para saber usar e ensinar o aluno a usar as tecnologias de internet, e-mails e ferramenta AVA (ambiente virtual de aprendizagem); a competência pessoal e de trabalho colaborativo em equipe para criação de um 
Id on Line Revista Multidisciplinar e de Psicologia

Id on Line Multidisciplinary Journal and Psycology

ambiente favorável. Entre elas, mencionamos e destacamos a competência pedagógica de "avaliação do material didático-pedagógico visando à proposição de melhorias de padrões de ensino e aprendizagem", fundamental para a mediação entre material e aluno, mas que só será possível com base em um diagnóstico do perfil da turma como consequência dos sucessivos encontros e interações entre os sujeitos.

A função pedagógica está relacionada à manutenção de um ambiente social amigável, que é essencial à aprendizagem online. O papel do professor em qualquer ambiente educacional é garantir que o processo educativo ocorra entre os alunos. No ambiente online, o tutor é um facilitador, conduzindo o grupo de maneira mais livre e permitindo aos alunos explorar o material do curso sem restrição.

A função gerencial envolve normas referentes ao agendamento do curso, ao seu ritmo, aos objetivos traçados, à elaboração de regras e à tomada de decisões.

A função técnica depende do domínio técnico do tutor, sendo então capaz de transmitir tal domínio de tecnologia aos seus alunos. Os tutores devem conhecer bem a tecnologia que usam para atuar como facilitadores do curso.

A função social significa facilitação educacional. O tutor é responsável por facilitar e dar espaço aos aspectos pessoais e sociais da comunidade online.

Nos escritos de Saraiva et al (2006), ao discutir os espaços de tensão nos eventos de tutoria a distância, ficam implícitas duas grandes habilidades fundamentais para a tutoria: a paciência e a perspicácia para lidar com as tensões da tutoria e os conhecimentos das ferramentas e abertura ao novo.

A nosso ver, a paciência é importante, pois, segundo os autores, os processos de capacitação usuais em EAD, seja qual for o aspecto focado, não são por si mesmos suficientes para dar conta da complexidade de situações que se vão criando à medida que os cursos vão sendo implementados (SARAIVA et al, 2006, p. 485).

Para esses autores, penetrar no mundo cibernético demanda não apenas domínios motores e apropriação de uma linguagem nova, mas também abandono de certos modos de lidar com o desconhecido. $\mathrm{O}$ medo de errar precisa ser abrandado para que o sujeito se permita navegar por rotas não previstas nem previsíveis. Os recursos tecnológicos, por não serem por si sós suficientes para atender a todos nas suas particularidades, necessitam da intervenção de tutores e monitores nos mecanismos de escuta e captura para suprir as necessidades de cada um (SARAIVA et al, 2006, p. 489).

Sá (1998) realizou um estudo comparativo entre os tutores presenciais e a distância. Com base em distintos resultados, sinaliza que o ensino a distância configura-se basicamente por: 
- ser acompanhado por um tutor;

- gerar atendimento ao aluno em consultas individualizadas ou em grupo, em situações em que o tutor mais ouve do que fala;

- preocupar-se com um processo educacional centrado no aluno;

- buscar a interatividade entre aluno e tutor sob outras formas, não descartada a ocasião para os "momentos presenciais";

- adaptar-se ao ritmo determinado pelo aluno dentro de seus próprios parâmetros;

- avaliar de acordo com parâmetros definidos, em comum acordo pelo tutor e pelo aluno;

- ser atendido pelo tutor, com horários flexíveis, lugares distintos e meios diversos.

É relevante esclarecer as semelhanças e diferenças do papel dos professores nas duas modalidades de educação (presencial e a distância) para evitar problemas na estruturação dos cursos a distância, para evitar uma possível desvalorização do trabalho do professor na $\mathrm{EaD}$ e para que o professor-tutor tenha consciência do seu papel e de suas funções.

No papel de tutor, o delineamento mais preciso pode favorecer as instituições que promovem a $\mathrm{EaD}$, na medida em que define as atribuições e os parâmetros do cargo, fornecendo subsídios para diversas práticas de Recursos Humanos, como seleção, treinamento, avaliação de desempenho e definição de salários, entre outras

No que tange à dimensão administrativa, não podemos deixar de mencionar algumas funções exclusivas do tutor a distância, como:

- auxiliar o professor nas correções das atividades a distância;

- auxiliar o professor na criação ou na intermediação dos fóruns de debate ou de apresentação;

- auxiliar o professor nas edições das seções e de conteúdos inseridos na sala de aula solicitados pelo professor responsável;

- fazer a verificação diária de dúvidas enviadas tanto por mensagens como pelo fórum de dúvidas, num período ideal de até 24 h;

- auxiliar o professor no lançamento de notas e feedback para os alunos no AVA;

- auxiliar o professor publicando avisos importantes no AVA. 
Id on Line Revista Multidisciplinar e de Psicologia

Id on Line Multidisciplinary Journal and Psycology

Segundo Bottentut e Coutinho (2015), um dos grandes desafios do tutor consiste em manter o interesse dos alunos e garantir a sua presença nos ambientes online. Esse indicador costuma ser medido pelas taxas de evasão apresentadas nos cursos. Embora seja importante ressaltar que são muitas as razões que levam os alunos a abandonar um curso a distância, é também relevante ter em mente que muitas dessas razões poderiam ser contornadas com o papel-chave do professor-tutor em todo o processo. Ou seja, se as ferramentas tecnológicas utilizadas no processo de tutoria forem fáceis de utilizar, se os conteúdos estiverem estruturados de forma didática, se o tutor providenciar efetivo apoio a distância, o interesse dos alunos tende a aumentar, garantindo o sucesso do curso.

\section{Tipos de Ferramentas Interativas}

\section{Ferramentas assíncronas}

Ferramentas assíncronas "são aquelas que independem de tempo e lugar e podem revolucionar o processo de interação entre professores e estudantes" (LINS, MOITA, 2009). Tendo como exemplos:

-E-mail, que é considerada a ferramenta mais utilizada na Internet e que permite a troca de mensagens e compartilhamento de informações; o envio e recebimento de textos simples, arquivos de áudio, planilhas eletrônicas, imagens, anexos (arquivos atachados), podendo utilizar dispositivos de segurança para criptografar as mensagens.

-Fórum ou Lista de discussão possibilita a comunicação entre membros de um projeto ou de pessoas interessadas em temas específicos; Podem ser abertas ou restritas a participação de novos indivíduos.

-Webblogs ou Blogs é um diário virtual. Sendo a ferramenta mais conhecida e utilizada no contexto educativo;

-FTP - file protocolo é disponibilização de arquivos contendo áudio, textos, imagens ou vídeo (MEHLECKE, TAROUCO, 2009).

\section{Ferramentas síncronas}

Ferramentas síncronas são aquelas que exigem a participação dos professores e estudantes em eventos marcados, com horários específicos para que possam acontecer. Ocorrem em tempo real (online), dão aos alunos da EAD e aos professores, como também a todos envolvidos na instituição, 
Id on Line Revista Multidisciplinar e de Psicologia

Id on Line Multidisciplinary Journal and Psycology

grupos e comunidades interação de forma instantânea e a sensação de perseverar a continuidade do seu curso.

O desenvolvimento da agilidade na comunicação acontece de forma harmoniosa no processo da aprendizagem, pela facilidade da relação entre professores-alunos, alunos-professores e alunosalunos, onde todos são envolvidos pela interação e a interatividade (LINS, MOITA, 2009). Tendo como exemplos:

\begin{abstract}
-Chat (Sala de bate-papo), meio com potencial didático a ser estudado, pouco utilizado nas atividades pedagógicas, permite a comunicação síncrona, entre distintas pessoas que se encontram conectada em determinado momento. Estudos na literatura sobre o uso pedagógico do chat ainda são iniciais, a maior parte destes materiais se limitam a assinalar suas características gerais, sem entrar em detalhes sobre suas possibilidades concretas. Assim, faz-se necessário realizar estudos experimentais relacionados com seu uso como ferramenta de comunicação e ferramenta pedagógica gerando aprendizagem e mecanismos de superação das dificuldades e limitações oferecidas no uso do Chat na aprendizagem (MERCADO, 2009)
\end{abstract}

-Videoconferência, que Segundo Santos N. (1998), é uma forma de comunicação interativa que permite que duas ou mais pessoas que estejam em locais diferentes possam se encontrar face-aface com áudio e comunicação visual em tempo real. Seu uso apresenta uma série de vantagens: economia de tempo, evitando o deslocamento físico para uma local especial e economia, com a redução dos gastos com viagens mais um recurso de pesquisa, já que a reunião pode ser gravada e disponibilizada posteriormente.

-Audioconferência, sistema de transmissão de áudio, recebido por um ou mais usuários simultaneamente. Disponibilização de arquivos contendo áudio, textos, imagens ou vídeo. (MEHLECKE, TAROUCO, 2009). A interação entre os indivíduos ocorre através de um canal de áudio onde pode ouvir e interagir; curso, palestra, reunião, entre outros. Canal de texto, pelo Chat em uma sala virtual, onde os participantes podem contribuir com perguntas, opiniões, fazendo suas colocações sem atrapalhar a fala do outro que está falando no momento. Esse tipo de ferramenta tem suas vantagens sobre as outras ferramentas sem precisar de muita sofisticação, permitindo sua real funcionalidade, com um computador com figurações mínimas; caixa de som; microfone ou um headphone; conexão com a internet, mesmo sendo uma linha discada.

-Teleconferência é todo tipo de conferência a distância em tempo real, envolvendo transmissão e recepção dos diversos tipos de mídia, com sons e imagens direto de um local.

Todos os tópicos supracitados têm a participação direta do tutor online para acompanhamento, avaliando e tirando dúvidas em tempo real dos alunos sobre os conteúdos trabalhados e propiciando a 
Id on Line Revista Multidisciplinar e de Psicologia

Id on Line Multidisciplinary Journal and Psycology

integração, o compartilhamento de informações entre todos. Sendo assim, o tutor torna-se o protagonista desta ação educativa, por fazer o elo entre o aluno e o professor. Aquele que permite a construção coletiva, construindo novos saberes e novos olhares sobre o real.

\section{Conclusao}

Diante do exposto, espera-se que o trabalho tenha respondido à problemática proposta, pois abrangeu a participação e as contribuições dos tutores a distância ao processo de ensino aprendizagem, sob seu ponto de vista e o ponto de vista dos professores, assim como constatou suas deficiências e necessidades de melhoria.

Também devemos insistir na formação da docência para os professores-tutores, para atuarem na $\mathrm{EaD}$, bem como na construção de outras metodologias que potencializam a comunicação interativa, oportunizando a participação ativa do aluno, numa pedagogia baseada na coautoria, na aprendizagem participativa e dialógica que rompe com o modelo clássico de comunicação e possibilita que os alunos exerçam a autonomia

Espera-se com esse estudo, contribuir para repensar a função dos tutores presenciais e a distância atuantes na modalidade de ensino à distância, tendo em vista que, acreditamos ser de fundamental importância a realização de formação inicial e continuada com esses profissionais, pois são eles que mantêm contato direto e diário com os alunos.

O tutor contribui para desenvolvimento integrado do indivíduo, em seus diferentes campos: pessoal, acadêmico, profissional. Por isso, é uma função do ensino à distância que não se restringe apenas à transmissão de conhecimentos, exercer a função de tutoria de um curso a distância requer características que estão além do domínio dos conteúdos e dos meios técnicos, implicando aportes pedagógicos específicos da função docente.

As ferramentas utilizadas, são meios de aprendizagem no ensino à distância, cabe aos alunos, tutores, professores, utilizá-las da forma orientada, para melhor aprendizagem.

Dentro do âmbito da Psicologia Aplicada a Educação, as contribuições para a prática escolar na Educação a Distancia, conscientes da necessidade de contribuir favoravelmente para a formação qualitativa de nossos acadêmicos, futuros professores, a fim de que possam atuar no seu contexto educacional, que traz novas exigências sociais, e sejam capazes de intervir e de contribuir para transformar em algum grau o meio em que vivem. 
Id on Line Revista Multidisciplinar e de Psicologia

Id on Line Multidisciplinary Journal and Psycology

\section{Referências}

ARETIO, Lorenzo García; CORBELlA, Marta Ruiz; FIGAREDO, Daniel Domínguez. De laeducación a distancia a laeducación virtual. Barcelona: Ariel, 2007.

BOTTENTUIT JUNIOR, J. B.; COUTINHO, M. C. As ferramentas da web 2.0 no apoio à tutoria na formação em e-learning. Disponível em:

http://repositorium.sdum.uminho.pt/bitstream/1822/7767/1/Afirse\%202008.pdf Acesso em 25 outubro . 2015.

BRASIL. Decreto Federal $n^{\circ} 5.800$, de 8 de junho de 2006.Dispõe sobre o Sistema Universidade Aberta do Brasil - UAB. Disponível em: <http://www.planalto.gov.br/ccivil_03/_Ato20042006/2006/Decreto/D5800.htm>. Acesso em: 08 jan. 2015.

Resolução CD/FNDE n' 26, de 5 de junho de 2009. Estabelece orientações e diretrizes para o pagamento de bolsas de estudo e de pesquisa a participantes da preparação e execução dos cursos dos programas de formação superior, inicial e continuada no âmbito do Sistema Universidade Aberta do Brasil (UAB). Disponível em: <http://ead.ufsc.br/files/2007/12/resolucao-no-26-5-de-junho09.pdf>. Acesso em: 10 jan. 2015.

Resolução CD/FNDE $\mathbf{n}^{\circ} 8$, de 30 de abril de 2010. Altera os incisos I a V do art. $9^{\circ}$, o $\S 1^{\circ}$ do art. 10 e o item 2.4 do Anexo I da Resolução CD/FNDE no 26/2009, que estabelece orientações e diretrizes para o pagamento de bolsas de estudo e de pesquisa a participantes da preparação e execução dos cursos dos programas de formação superior, inicial e continuada no âmbito do Sistema Universidade Aberta do Brasil (UAB). Disponível em: <www.fnde.gov.br/index.php/rockres2010/4575res0830042010/download>. Acesso em: 10 jan. 2015

DANTAS, E. M.; TROLEIS, A. L. Entre rosas e espinhos, a avaliação e a educação a distância. Holos: Revista de Divulgação Científica e Tecnológica do Instituto Federal de Educação, Ciência e Tecnologia do Rio Grande do Norte, ano 29, v. 1, p. 256-267, 2013. Disponível em: <http://www2.ifrn.edu.br/ojs/index.php/HOLOS/article/view/1026/655>. Acesso em: 03 jan. 2015. FACINTER. Manual do tutor. $2006 . \quad$ Disponível em: <http://unico.facinter.br/download/manualdotutor-def.pdf>. Acesso em: 04 jan. 2015.

FREIRE, Paulo. Conscientização: teoria e prática da libertação: uma introdução ao pensamento de Paulo Freire. São Paulo: Moraes, 1980.

Extensão ou comunicação? Rio de Janeiro: Paz e Terra, 1983. O mundo hoje, v. 24.

. Pedagogia do oprimido. São Paulo: Paz e Terra, 1987.

GEIB. Lorena Teresinha Consalter, et al. A tutoria acadêmica no contexto histórico da educação. Revista Brasileira de Enfermagem. Brasília, v. 60(2), p. 217-220, mar/abr. 2007.

LINS, R. M.; MOITA, M. H. V. Interatividade na Educação a Distância. Disponível em:http://www.abepro.org.br/biblioteca/ENEGEP2006_TR540364_8555.pdf Acesso em 25 outubro . 2015.

LOBO NETO, Francisco José da Silveira. Regulamentação da Educação a Distância: caminhos e descaminhos. In Silva, Marco (org.). Educação online. São Paulo: Edições Loyola, 2003. 
Id on Line Revista Multidisciplinar e de Psicologia

Id on Line Multidisciplinary Journal and Psycology

MEHLECKE, Querte, T.C.; TAROUCO, Liane. Revista RENOTE. V. 1 No 1, Fevereiro, 2003.

MEHLECKE, Querte, T.C.; GUEDES, Adriana T..ESTRATÉGIAS DO PROFESSOR PARA PROMOVER A INTERAÇÃO DOS ALUNOS NAS AULAS A DISTÂNCIA ON-LINE. Revista Liberato. Revista Liberato. v. 7, n. 8, jul./dez. 2006. Novo Hamburgo, RS, Brasil. I

MILL, D.; ABREU-E-LIMA, D.; LIMA, V.S.; TANCREDI, R.M.S.P. O desafio de uma interação de qualidade na educação a distância: o tutor e sua importância nesse processo. Cadernos da Pedagogia. São Carlos, ano 2, v. 2, n. 4, p. 14; 112-127, ago./dez. 2008. Disponível em: <http://www.sead.ufscar.br/outros/artigo-mill. $>$ Acesso em: 05 jan. 2015.

MORAES, Marialice de; VIEIRA, Eleonora Milano Falcão. Introdução à EaD. 2.ed. Florianópolis: Departamento de Ciências Contábeis/UFSC, 2009.

MORAES, Marialice; TORRES, Patrícia Lupion. A monitoria online no apoio ao aluno a distância: o modelo do LED. Disponível em: <http://pead.ucpel.tche.br/revistas/index.php/colabora/article/viewFile/36/33>. Acesso em: 01 jan. 2015

. Ensino e aprendizagem inovadores com tecnologias audiovisuais e telemáticas. In: MORAN, José Manuel; MASETTO, Marcos Tarciso; BEHRENS, Maria Aparecida. Novas tecnologias e mediação pedagógica. Campinas: Papirus, 2000.

NOGUEIRA, R. C. C.; BOTH, I. J. A importância do tutor em Educação a Distância (EaD). Cadernos Intersaberes, v. 1, n. 1, jul./dez. 2012. Disponível em: http://www.grupouninter.com.br/intersaberes/index.php/cadernointersaberes/article/view/309/184.

Acesso em:25 jul. 2013.

PALLOFF, R.; PRATT, K. Construindo comunidades de aprendizagem no ciberespaço. Porto Alegre: Artmed, 2002.

PERNÍAS, Pedro. Educação a distância faz ganhar tempo. Disponível em: www.novaescola.abril.com.br/notícia/expoente/pernias/htm. Acesso em: 17 fev. 2002.

PRETI, Oreste. Educação a distância: inícios e indícios de um percurso. Cuiabá: NEAD/IE-UFNT, 1996.

RODRIGUES, Rosângela Schwarz. Modelo de planejamento para Educação a Distância em Cooperação Universidade-Empresa. Tese Programa de Pós-Graduação em Engenharia de Produção. Universidade Federal de Santa Catarina. Florianópolis, 2004.Disponível em:

<https://repositorio.ufsc.br/bitstream/handle/123456789/87716/208818.pdf?sequence=1> Acesso em: 09 jan. 2015.

SÁ, Iranita. Educação a distância: processo contínuo de inclusão social. Fortaleza: CEC, 1998.

SARAIVA, T. M.; PERNIGOTTI, J. M.; BARCIA, R. M.; LAPOLLI, E. M. Tensões que afetam os espaços de Educação a Distância. Psicologia em Estudo, Maringá, v. 11, n. 3, p. 483-491, set./dez. 2006. 
Id on Line Revista Multidisciplinar e de Psicologia

Id on Line Multidisciplinary Journal and Psycology

\section{Como citar este artigo (Formato ABNT):}

DIAS, FA.O.; SILVA, A.M.S. O Uso de Ferramentas na Educação a Distãncia e o Papel do Tutor. Id on Line Revista Multidisciplinar e de Psicologia, Julho de 2016, vol.10, n.30, Supl 3, p. 16-33. ISSN 1981-1179.

Recebido: 18/02/2016.

Aceito: $20 / 07 / 2016$ 